\title{
Improvement of Stress Resistance and Quality of Life of Adults with Nervous Restlessness after Treatment with a Passion Flower Dry Extract
}

\author{
Judith Gibbert ${ }^{\mathrm{a}}$ Fabian Kreimendahl ${ }^{\mathrm{a}}$ Jennifer Lebert ${ }^{\mathrm{b}} \quad$ Reinhard Rychlik $^{\mathrm{a}} \quad$ Inga Trompetter $^{\mathrm{b}}$ \\ a Institute of Empirical Health Economics, Burscheid, Germany; \\ bPASCOE pharmazeutische Präparate $\mathrm{GmbH}$, Giessen, Germany
}

\section{Keywords}

Passiflora incarnata - Nervous restlessness .

Resilience · Quality of life · Non-interventional study

\section{Summary}

Background: The passion flower dried ethanolic extract investigated in this non-interventional study has well-documented calmative effects and good tolerability. We investigated the effects of this extract on the stress resistance (resilience) and quality of life ( $\mathrm{QoL}$ ) of patients suffering from nervous restlessness. The addiction potential of the drug and the course of symptoms were also evaluated. Methods: Adult patients aged $\leq 95$ years with the diagnosis 'nervous restlessness' were treated for 12 weeks with a dried ethanolic extract of passion flower (Passiflora incarnata L.). Standardized questionnaires were used to evaluate the resilience (RS-13), OoL (EQ-5D including EQ-VAS), and the addiction potential (BDEPQ). Results: After 12 weeks of treatment, significant $(p<0.001)$ improvements were measured in the patients' resilience (RS-13: from 52.1 to 67.7 points) and QoL (EQ-VAS: from 47.9 to 75.0 points). Also, the mean BDEPO score was significantly ( $p<0.001$ ) reduced (from 23.0 to 19.3 points). The mean values of all accompanying symptoms (inner restlessness, sleep disturbance, exhaustion, fear, lack of concentration, transpiration, nausea, trembling, and palpitation) improved significantly ( $p<0.001)$. Tolerability of treatment was rated as 'very good' or 'good' by the majority of the patients. Three cases of mild adverse events (tiredness) were reported. Conclusion: The passion flower extract investigated in the present study appears to be effective in improving resilience and QoL in patients suffering from nervous restlessness and is well tolerated.

(c) 2017 The Author(s). Published by S. Karger GmbH, Freiburg

\author{
Schlüsselwörter \\ Passiflora incarnata · Nervöse Unruhezustände · \\ Resilienz · Lebensqualität · Nichtinterventionelle Studie
}

\section{Zusammenfassung}

Hintergrund: Der in dieser nichtinterventionellen Studie geprüfte ethanolische Passionsblumen-Trockenextrakt ist für seine beruhigende Wirkung und gute Verträglichkeit bekannt. In der vorliegenden Studie wurde die Wirkung dieses Extraktes auf die Stressresistenz (Resilienz) und Lebensqualität bei Patienten, die an nervösen Unruhezuständen litten, untersucht. Zudem wurden auch das Abhängigkeitspotenzial und der allgemeine Symptomverlauf analysiert. Methoden: Erwachsene Patienten im Alter von $\leq 95$ Jahren mit der Diagnose «nervöse Unruhezustände" wurden über 12 Wochen mit einem ethanolischen Passionsblumen-Trockenextrakt (Passiflora incarnata L.) behandelt. Mittels standardisierter Fragebögen wurden die Resilienz (RS-13), die Lebensqualität (EQ-5D inklusive EQ-VAS) und das Abhängigkeitspotenzial (BDEPQ) erfasst. Ergebnisse: Nach 12 Wochen Therapie wurden signifikante $(p<0,001)$ Verbesserungen für die Resilienz (RS-13: von 52,1 auf 67,7 Punkte) und die Lebensqualität (EQ-VAS: von 47,9 auf 75,0 Punkte) beobachtet. Auch die BDEPQWerte waren signifikant $(p<0,001$ ) reduziert (von 23,0 auf 19,3 Punkte). Die Durchschnittswerte aller begleitenden Symptome (innere Unruhe, Schlafstörungen, Erschöpfung, Angst, Konzentrationsschwäche, Schwitzen, Übelkeit, Zittern und Herzklopfen) verbesserten sich signifikant ( $p<0,001$ ). Die Verträglichkeit der Behandlung wurde von der Mehrheit der Patienten mit "sehr gut" bzw. "gut» bewertet. Drei Fälle leichter unerwünschter Arzneimittelwirkungen (Müdigkeit) traten auf. Schlussfolgerung: Der in der vorliegenden Studie untersuchte Passionsblumenextrakt kann die Resilienz und Lebensqualität bei Patienten, die an nervösen Unruhezuständen leiden, wirksam verbessern und ist gut verträglich.

\section{KARGER}

Fax +497614520714

Co 2017 The Author(s)
Published by S. Karger GmbH, Freiburg
Open access

This article is licensed under the Creative Commons AttributionNonCommercial-NoDerivatives 4.0 International License (CC BY-NCND 4.0) (http://www.karger.com/Services/OpenAccessLicense). Usage mifed materil requires written permission. an anstrbution of
Dr. rer. nat. Inga Trompetter
PASCOE pharmazeutische Präparate GmbH
Schiffenberger Weg 55, 35394 Giessen, German

inga.trompetter@pascoe.de 


\section{Introduction}

Nervous restlessness (International Classification of Diseases 10 (ICD-10) code R45.1) is a frequent impairment of well-being. According to the German Federal Health Report 2015, the prevalence of the diagnosis has more than doubled between 2000 and 2014 based on inpatient records. The most prominent symptom, inner restlessness, occurs in $41.3 \%$ of all patients in primary medical care [1]. Persistent nervous restlessness impairs cognitive functions, such as decision-making, and disturbs normal activities of daily life. Patients also describe physical symptoms such as sleeping problems, nausea, or palpitations. Furthermore, they perceive chronic physical or mental stress, exhaustion, grief, fear, and lack of concentration.

Pharmacological treatment options for nervous restlessness are various, ranging from the use of homeopathic and herbal remedies up to the prescription of synthetic drugs, such as benzodiazepines. However, as benzodiazepines display a high addiction potential, they are contraindicated for long-term therapy [2]. Dried extracts of passion flower (Passiflora incarnata L.) constitute a phytotherapeutic alternative. Passion flower has a long, worldwide tradition as medicinal plant [3] and is used for the treatment of nervousness, anxiety, hysteria, and neurasthenia, but also for mild infections, dyspepsia, and deworming. In current recommendations for use, its mild sedative and anxiolytic effects are prioritized (for an overview, see [4]). The monograph of the Committee on Herbal Medicinal Products (HMPC) indicates its traditional use for the relief of mild symptoms of mental stress and the treatment of sleep disorders [5].

In vitro studies on the effects of a dried extract of $P$. incarnata revealed a modulation of the gamma-aminobutyric acid (GABA) neurotransmission system as its possible mechanism of action. This includes inhibition of synaptic reuptake of GABA as well as binding at the $\mathrm{GABA}_{\mathrm{A}}$ (ionotropic) and $\mathrm{GABA}_{\mathrm{B}}$ (metabotropic) receptors $[6,7]$. Experimental data suggest that binding to the GABA site of the $\mathrm{GABA}_{\mathrm{A}}$ receptor is likely to contribute to the pharmacological effect of the $P$. incarnata extract. In contrast, the benzodiazepine site and the ethanol site of the $\mathrm{GABA}_{\mathrm{A}}$ receptor were not affected by the extract. These data suggest a low addiction potential and are consistent with data showing passion flower extracts to be effective in treating opioid withdrawal symptoms, such as sleep disorders and anxiety [8-10]. However, a systematic investigation confirming the low addiction potential of passion flower after long-term treatment (for more than 6 weeks) is lacking.

The dried ethanolic extract used in the present study is approved for the treatment of nervous restlessness. Its pharmacological effects have already been demonstrated in 2 randomized, placebo-controlled clinical trials with neurophysiological outcomes $[11,12]$. In the first study, significant changes in the electroencephalography (EEG) profile indicative of calming and relaxing effects were observed in healthy volunteers after verum intake, without any cognition-attenuating side effects [11]. In the second study, the calmative effect of the extract was confirmed in subjects suffering from examination anxiety [12].

The primary aim of this non-interventional study was to investigate the effect of a dried ethanolic extract of passion flower (Pascoflair $^{\circledR}$ ) on the stress resistance (resilience) and quality of life (QoL) of patients suffering from nervous restlessness. In addition, the addiction potential of the extract after long-term treatment and the general course of symptoms were evaluated.

\section{Material and Methods}

Study Design

The multicenter, prospective non-interventional study was conducted according to $\$ 4$ (23) sentence 3 and $\$ 67$ (6) of the German Medicines Act (Arzneimittelgesetz (AMG)). The concept and design of the study, as well as its ethical validity and performance, are based on the current recommendations of the German Bundesinstitut für Arzneimittel und Medizinprodukte (BfArM, German Federal Institute for Drugs and Medical Devices) and are in accordance with the Declaration of Helsinki and Good Clinical Practice. The study was registered at ClinicalTrials.gov (trial registration number: NCT 02651922).

Before the start of this study, the involved physicians received a briefing on the observational plan, the ethical, legal, and scientific basis of this non-interventional study, the treatment allocation procedure, and the treatment schedule, as described in the study protocol. Data were collected using 3 standardized questionnaires and were each completed on 3 occasions: before treatment (visit 1 , baseline), after approximately 4 weeks of treatment (visit 2), after approximately 12 weeks of treatment (visit 3 ) (table 1).

Table 1. Study course

\begin{tabular}{llll}
\hline Assessment of & Visit 1 & Visit 2 & Visit 3 \\
\hline Sociodemographic data (sex, age, current professional situation, marital status, insurance) & $\mathrm{X}$ & - & - \\
Psychosocial stress factors & $\mathrm{X}$ & - & - \\
Duration of symptoms and previous therapy due to inclusion diagnosis/ Effectiveness and & $\mathrm{X}$ & - & - \\
$\quad$ tolerability of previous therapy due to inclusion diagnosis & & & $\mathrm{X}$ \\
Concomitant non-drug and drug therapies due to inclusion diagnosis & - & $\mathrm{X}$ & $\mathrm{X}$ \\
Patient questionnaire on resilience: RS-13 & $\mathrm{X}$ & $\mathrm{X}$ & $\mathrm{X}$ \\
Patient questionnaire on QoL: EQ-5D including EQ-VAS & $\mathrm{X}$ & $\mathrm{X}$ & $\mathrm{X}$ \\
Patient questionnaire on drug dependence: BDEPQ & - & $\mathrm{X}$ & $\mathrm{X}$ \\
Common symptoms of nervous restlessness & - & $\mathrm{X}$ & $\mathrm{X}$ \\
Effectiveness, tolerability of study medication, and compliance & - & $\mathrm{X}$ & $\mathrm{X}$ \\
Drug changes (dosage, newly prescribed, withdrawn) & - & $\mathrm{X}$ & $\mathrm{X}$ \\
Adverse reactions & - & \\
\hline QoL = Quality of life; EQ = EuroQol; VAS = visual analog scale; BDEPQ = benzodiazepine dependence questionnaire.
\end{tabular}




\section{Participants}

Enrollment of the participants followed the recommendations of the BfArM [13]: The attending physician selected the patients for participation in the study after first deciding on the appropriate treatment for each patient. Entry into the study was complete when the informed written consent and a data privacy policy statement had been signed by the patient. All participants received information about possible unwanted side effects and the possibility to cancel participation at any time without any negative impact on the treatment. The identity of each patient was disguised via a pseudonymization procedure (patient identification numbers were determined).

Inclusion criteria were: previous diagnosis by a physician of nervous restlessness, age $\geq 18$ years, signed informed consent to study participation. Exclusion criteria were: current drug or alcohol addiction, pregnancy or breastfeeding, hypersensitivity to passion flower extract or to other components of the medication, intake of benzodiazepines during the observational study period.

All patients were treated with a standardized extract of passion flower (Pascoflair ${ }^{\circledR}$ ) in accordance with the prescription information leaflet. Each coated tablet contained $425 \mathrm{mg}$ of the dried extract from passion flower herb (P. incarnata L.) (drug/extract ratio 5:1 to 7:1, extraction solvent: ethanol 50 vol- $\%$ ). The individual dosages used in this study were decided by the respective physicians

\section{Variables Studied and Statistical Methods}

An overview of the documented aspects is given in table 1.

- The patient's resilience was measured using the patient questionnaire, RS$13[14,15]$, which applies a reliance scale ranging from 13 (lowest stress resistance) to 91 (highest stress resistance). The statistical significance of any changes in the mean score was calculated using the Friedman test and subsequently using the Wilcoxon 2-sample tests, in cases of significant changes. For multiple comparisons, the alpha level was adjusted to $1.6 \%$ after applying a Bonferroni correction.

- The patient's QoL was determined using the EuroQol Group patient questionnaire, EQ-5D [16-18], in combination with a visual analog scale (EQVAS). The EQ-5D assesses 5 aspects of QoL: mobility, self-care, usual activity, pain/discomfort, and anxiety/depression. An EQ-5D profile score of 0 points represents the worst QoL (death), while 1 point stands for full health. Data analysis was performed according to the EuroQol manual. The EQ-VAS ranges from 0 (worst QoL) to 100 (best QoL). The data were then tested for differences using the Friedman test with subsequent Wilcoxon post-hoc tests in case of significance between group results.

- The addiction potential of the study medication was assessed using the benzodiazepine dependence questionnaire (BDEPQ) [19, 20]. This internationally recognized patient questionnaire was designed to measure the dependence on benzodiazepine tranquilizers, sedatives, and hypnotics. High scores indicate greater risk of future withdrawal symptoms if medication is continued and increased risk of dependency. Accordingly, a BDEPQ score of 0 points represents no dependency while the maximum of 85 points indicates severe dependency. Each item is rated on a 4 -point Likert scale referring to experiences within the last month. The presence of a normal distribution was checked using the KolmogorovSmirnov test. Differences between visits 2 and 3 were analyzed by the paired t-test.

- Severity of common symptoms (inner restlessness, sleep disturbance, exhaustion, fear, lack of concentration, transpiration, nausea, trembling, and palpitation) was assessed by the physician and evaluated by means of a numeric rating scale (NRS) (10-point NRS: $0=$ no symptoms, $10=$ very severe symptoms). A patient was defined as 'affected' if a symptom was rated with a score $\geq 1$ point on the NRS at the start of the study. For patients who left the study prior to visit 3 , the last value obtained during treatment (visit 2 after 1 week) (if available) was used for analysis. Missing data were imputed with the last available observation (according to the last observation carried forward' (LOCF) method). Changes from baseline were analyzed by means of the 2-sided 1-sample t-test.
Table 2. Sociodemographic parameters of the study population at visit 1 $(\mathrm{N}=154)$

\begin{tabular}{|c|c|c|}
\hline Variable & Mean & $\pm \mathrm{SD}$ \\
\hline Age, years & 47.9 & 17.1 \\
\hline Variable & $\mathrm{N}$ & $\%^{\mathrm{a}}$ \\
\hline \multicolumn{3}{|l|}{ Sex } \\
\hline Female & 115 & 75.2 \\
\hline Male & 38 & 24.8 \\
\hline Missing data & 1 & - \\
\hline \multicolumn{3}{|l|}{ Family status } \\
\hline Widowed & 6 & 4.0 \\
\hline Divorced & 17 & 11.3 \\
\hline Married & 91 & 60.3 \\
\hline Single & 36 & 23.8 \\
\hline Others & 1 & 0.7 \\
\hline Missing data & 3 & - \\
\hline \multicolumn{3}{|l|}{ Employment status } \\
\hline Employed & 96 & 62.3 \\
\hline Not employed & 58 & 37.7 \\
\hline \multicolumn{3}{|l|}{ Insurance type } \\
\hline Statutory & 129 & 83.8 \\
\hline Private & 25 & 16.2 \\
\hline \multicolumn{3}{|l|}{ Psychosocial stress factors } \\
\hline Yes & 118 & 77.6 \\
\hline No & 34 & 22.4 \\
\hline Missing data & 2 & - \\
\hline \multicolumn{3}{|l|}{ Previous medication for nervous restlessness } \\
\hline Yes & 48 & 32.0 \\
\hline No & 102 & 68.0 \\
\hline Missing data & 4 & - \\
\hline Variable & Mean & $\pm \mathrm{SD}$ \\
\hline $\begin{array}{l}\text { Duration of nervous restlessness since first } \\
\text { symptoms, years }\end{array}$ & 2.74 & 5.47 \\
\hline $\begin{array}{l}\text { Duration of nervous restlessness since first } \\
\text { treatment, years }\end{array}$ & 1.4 & 3.9 \\
\hline
\end{tabular}

aPercentages based on valid data (excluding missing data).

$\mathrm{SD}=$ Standard deviation .

- Effectiveness and tolerability of the study medication and patient compliance were documented via a 5-point Likert scale (very good, good, satisfactory, bad, very bad) at visits 2 and 3 . These data were not analyzed by explorative statistics.

All data were checked for plausibility, recorded and then analyzed with SAS 9.4 for Windows, MS Excel 2007, and MS Access 2007, or higher versions.

\section{Results}

From September 2014 to June 2015, 22 physicians from Germany recruited 156 patients. 2 patients were excluded completely from the analysis because they met the exclusion criterion 'additional intake of benzodiazepines'. Therefore, the overall study population at the time point of visit 1 consisted of 154 patients. Six patients discontinued the study after visit 1 (documented at visit 2), and another 4 patients, after visit 2 (documented at visit 3). Multi- 
Fig. 1. Intensity and development of symptoms of nervous restlessness. a Mean intensity of symptoms $\pm 95 \% \mathrm{Cl}$, evaluated via a 10 -point NRS ( $0=$ no symptom, $10=$ very severe). All changes were significant (visits 1 to 3 : $\mathrm{p}<0.001$ ). b Percentage of patients with improved, unchanged or deteriorated symptoms between visit 1 (pre-treatment) and visit 3 (after 12 weeks of treatment). Number of affected patients at visit 1 : inner agitation $(\mathrm{n}=$ 153), insomnia ( $\mathrm{n}=$ 149), exhaustion ( $\mathrm{n}=$ $151)$, anxiety ( $\mathrm{n}=143)$, lack of concentration ( $\mathrm{n}=146)$, sweating $(\mathrm{n}=$ 122), nausea $(\mathrm{n}=94)$, tremors $(\mathrm{n}=109)$, palpitations $(\mathrm{n}=137)$, other $(\mathrm{n}=28)$. CI = Confidence interval; NRS = numeric rating scale. a) Intensity of symptoms across treatment period

b) Development of symptoms between first visit and end of observation

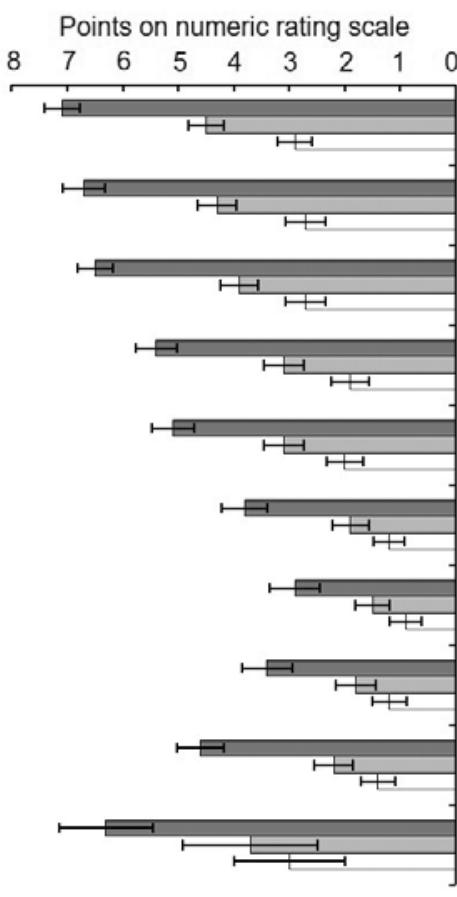

aVisit $1 \square$ Visit $2 \square$ Visit 3
Proportion of patients in \%

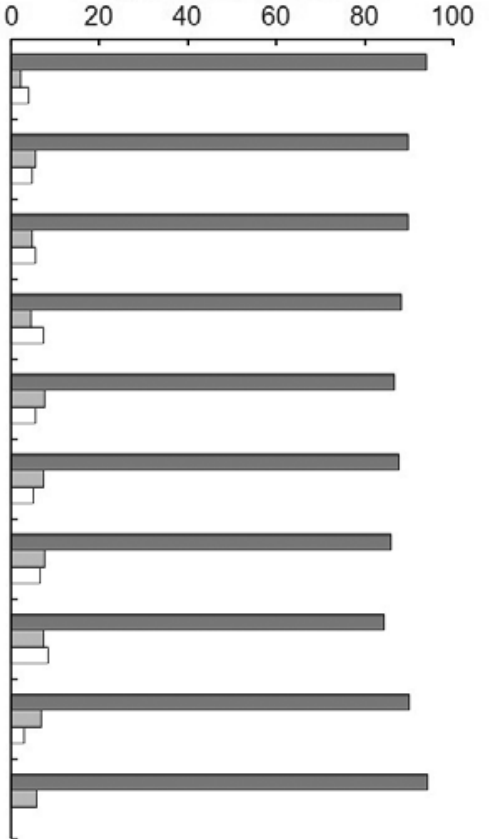

घImproved $\square$ Unchanged $\square$ Deteriorated ple answers were given concerning the reasons for these study drop-outs: patient's request (5 patients), adverse reaction ( 2 patients), or lack of expected efficacy (5 patients). After the planned observation period of 12 weeks, 5 patients discontinued the therapy. However, as these patients had complete documentation of all 3 visits, they were not counted as 'drop-outs'.

\section{Sociodemographic Data and Patient History Data}

The sociodemographic data of the 154 patients are summarized in table 2. More female (75.2\%) than male patients (24.8\%) participated in this study. The mean age was 47.9 years, with a maximum of 95 years of age. Most patients (83.8\%) had state insurance; the others (16.2\%) had private insurance. The majority $(60.3 \%)$ of the patients was married; $23.8 \%$ were single and $11.3 \%$ divorced. Overall, $25.3 \%$ of the participants had at least 1 child aged $0-17$ years. At baseline, $62.3 \%$ of the patients were employed. The non-employed patients (37.7\%) were retired, housewife/-husband, unemployed, students, or apprentices. The majority of the patients (77.6\%) reported psychosocial stress factors (multiple answers were possible), such as marital problems (33.1\%), high workload (31.4\%), financial problems (25.4\%), problems at work (25.4\%), a double burden of job and children (19.5\%), care of or coping with ailing dependents (9.3\%).

The inclusion diagnosis of nervous restlessness (ICD-10 code: R45.1 restlessness and agitation) was established at, on average, 2.7 years (range: 0 to $>35$ years) prior to the study, with most patients $(75 \%)$ having had their diagnosis established at $\leq 2.1$ years prior to the study. Treatment of nervous restlessness began, on average, 1.4 years (range: 0 to $>24$ years) prior to the study. Previous medical treatment was documented for 48 out of 154 patients. Benzodiazepines and antidepressants (such as selective serotonin reuptake inhibitors) were the most frequent medicines used to treat nervous restlessness (46.8\%), followed by herbal drugs (such as $\mathrm{Hy}$ pericum preparations) (34.0\%) and homeopathic agents (12.8\%). The reasons for treatment change (multiple answers were allowed) were lack of effect of previous medication (59.1\%), patient's request (36.4\%), adverse drug reaction (22.7\%), or drug dependence (6.8\%).

The average daily dosage of the study medication was 2.4 tablets per day and the most frequent dosage was 1 tablet 3 times per day, both of which were in accordance with the recommendations in the prescription information leaflet. A change in the dose of the study medication was documented for 6 patients at visit 2 and for 13 patients at visit 3 .

\section{Resilience}

Using the RS-13 questionnaire, the mean resilience score increased during treatment: 52.1 (95\% confidence interval (CI) 49.654.6) (visit 1), 61.9 (95\% CI 59.6-64.2) (visit 2), 67.7 (95\% CI 65.370.2 ) (visit 3). All changes were significant (Friedman test, $\mathrm{p}<0.001$; Wilcoxon 2-sample post-hoc tests, $\mathrm{p}<0.001$ for all comparisons).

\section{Quality of Life}

A significant increase in QoL from visit to visit was measurable by a significantly improved EQ-5D profile and EQ-VAS scores (Friedman test, $\mathrm{p}<0.001$; Wilcoxon 2-sample post-hoc tests, $\mathrm{p}<$ 0.001 for all comparisons). The mean EQ-5D profile score increased from 0.82 (95\% CI 0.79-0.85) (visit 1) to 0.90 (95\% CI 
Table 3. General tolerability at visit $2(\mathrm{~N}=148)$ and visit $3(\mathrm{~N}=144)$

\begin{tabular}{lccccc} 
& \multicolumn{2}{c}{ Visit 2} & & \multicolumn{2}{l}{ Visit 3} \\
\cline { 2 - 3 } \cline { 5 - 6 } & $\mathrm{N}$ & $\%^{\mathrm{a}}$ & & $\mathrm{N}$ & $\%^{\mathrm{a}}$ \\
\hline Very good & 109 & 73.6 & & 125 & 87.4 \\
Good & 35 & 23.6 & 17 & 11.9 \\
Satisfactory & 2 & 1.4 & & 1 & 0.7 \\
Bad & 1 & 0.7 & & 0 & 0 \\
Very bad & 1 & 0.7 & & 0 & 0 \\
Missing data & - & - & 1 & - \\
\hline aPercentages based on valid data (excluding missing data). & \\
\hline
\end{tabular}

0.87-0.92) (visit 2) to 0.92 (95\% CI 0.90-0.95) (visit 3). The number of patients reporting no anxiety or depression increased from 16 at baseline to 83 at visit 3. The improved QoL was also reflected by the mean EQ-VAS scores: 47.9 (95\% CI 44.8-51.0) (visit 1), 64.6 (95\% CI 61.8-67.4) (visit 2) and 75.0 (95\% CI 72.0-78.0) (visit 3). The Kolmogorov-Smirnoff test performed prior to the analyses showed that the data were not normally distributed at all visits.

\section{Risk of Drug Dependence}

The mean BDEPQ score was 23.0 (95\% CI 21.4-24.6) points, after 4 weeks of treatment (visit 2 ), and decreased significantly by 3.6 points ( $\mathrm{t}$-test for paired samples, $\mathrm{t}=7.31, \mathrm{df}=133, \mathrm{p}<0.001$ ) to 19.3 (95\% CI 17.5-21.1) points after 12 weeks of treatment (visit 3).

\section{Course of Symptoms}

A broad spectrum of psychological and physical symptoms were observed in the patients $(\mathrm{n}=154$ patients $=100 \%)$ (multiple answers were allowed): inner restlessness (99.4\%), sleep disturbance (96.8\%), exhaustion $(98.1 \%)$, fear $(92.9 \%)$, lack of concentration (94.8\%), transpiration (79.2\%), nausea (61.0\%), trembling (70.8\%), and palpitation $(89.0 \%)$. In single cases, further symptoms such as pain, diarrhea, or tension were reported. A significant reduction in mean symptom intensity was measured from visit to visit for all symptoms (t-test for paired samples, $\mathrm{p}<0.001$ for all symptoms and visits) (fig. 1a). The NRS analysis showed an improvement in $84.3 \%$ of the patients reporting 'trembling' and in $93.8 \%$ reporting 'inner restlessness' between baseline and the end of observation (fig. 1b). In a few cases, 1 or more symptoms remained unchanged or deteriorated. The general effectiveness was rated as 'very good' or 'good' by the physicians for most of the patients (visit 2: 77.0\%, visit 3: 91.6\%). Even for the 9 patients with a disease duration of $\geq 15$ years, a 'very good' or 'good' effectiveness was documented at the end of observation by the physician in 8 participants, and a satisfactory effectiveness in the remaining 1 patient.

\section{Tolerability, Safety and Compliance}

Treatment tolerability was reported by the physicians as 'very good' or 'good' for most of the patients (visit 2: $97.2 \%$, visit 3: 99.3\%) (table 3). Adverse events were reported for 3 patients, all at visit 2 . In 1 case, mild tiredness was reported. This patient continued the study and recovered without a change in study medication.
A second patient developed tiredness but was suffering from a common cold at this time. In the third case, a patient with an anxiety disorder reported tiredness and insensitivity. These 2 patients discontinued the study, but recovered completely without further medical treatment.

Assessment of the compliance was 'very good' or 'good' in $95.3 \%$ of the patients at visit 2 and in $97.9 \%$ of the patients at visit 3 .

\section{Discussion}

A diagnosis of nervous restlessness is often accompanied by difficult personal circumstances, such as the psychosocial problems reported by the majority of the patients in this study. This relationship between chronic stress and psychological problems has also been shown in the German Health Interview and Examination Survey for Adults (DEGS1), a German epidemiological study that confirms the importance of chronic stress as a health risk [21]. The ability to cope with stress (resilience) in addition to challenges of everyday life is dependent on several factors, such as personality, health, and social environment. The lower the resilience, the more likely are typical symptoms like inner restlessness, sleep disturbance, fear, and/or physical problems.

The results of this non-interventional study clearly show that resistance to stress significantly increases during treatment with the investigated passion flower extract. This is accompanied by a significant improvement of typical symptoms such as inner restlessness, fear, sleep disturbance, and exhaustion. These findings are consistent with previously reported calmative effects, anxiolytic properties, and positive impact on sleep observed in earlier studies and partly with different passion flower extracts [22-25].

Overall, both the psychological and the psychosomatic symptoms of the affected patients improved. This is also reflected by a significant increase in QoL. The mean EQ-VAS value ( \pm standard deviation (SD)) in the German healthy population is reported as 77.1 ( \pm 17.8 ) [26]. The QoL of our patient cohort was clearly negatively affected at the start of the study, with a mean EQ-VAS value of 47.9. During treatment, the value increased to a mean level of 75.0, which is within the reported normal range. This trend was also supported by a noticeable increase in the number of unaffected patients in the EQ-5D category 'anxiety/depression'.

In addition to the anxiolytic effects of passion flower mediated via the GABAergic system $[6,7,27]$, there is growing evidence that the antioxidant properties of the constituent flavonoids also contribute to the mechanism of action. As psychological stress conditions are associated with increased pro-oxidant and pro-inflammatory processes [28], these antiradical effects are also of great relevance. In vitro experiments revealed that ethanolic extracts, such as the one used in this study, extinguish oxidative free radicals more effectively than aqueous extracts of passion flower. The highest antiradical effect was measured for isovitexin and orientin [29], which are the 2 major flavonoids of the extract examined in this study [27]. Isovitexin has been identified in vitro as a neuroprotective agent against glutamate-induced cell damage [30]. Due to its 
antioxidant activity, orientin protects human erythrocytes in vitro from oxidative damage by attenuating oxidative stress; it protects antioxidative enzyme activities and preserves the integrity of the erythrocyte structure [31]. In an in vitro and in vivo study, antiinflammatory properties have been measured [32]. Of particular note, in an in vivo mouse model, orientin exerts antidepressantlike effects on mice, specifically by improving oxidative stress, neurotransmission, and neuroplasticity [33].

Restoring maintenance of mental concentration is an important goal in treatment of nervous restlessness and related symptoms. This is critical for employed people and car drivers but also for the elderly because even mild cognitive impairment is associated with higher rates of falls in this group [34]. Cognitive capacity after intake of the passion flower extract used in this study has been analyzed previously in a clinical trial using EEG measurements and different cognitive tests. After a single drug administration of the maximum daily dose, there was no detectable difference in cognitive function compared to that after intake of placebo [11]. In the current study, just 3 patients reported transient tiredness, but without any confirmed relationship to the study medication. In most of the patients, symptoms such as lack of concentration, sleep disturbance and exhaustion improved during treatment, indicating a good mental performance also with prolonged use of the passion flower extract.

Drug dependence is not uncommon for calmative medications. Physiological dependence is, for example, a particularly wellknown side effect of benzodiazepines. Herbal medicines have, in general, the reputation of being without any addiction potential. In this non-interventional study, the potential psychological or physiological dependence on passion flower was addressed for the first time and both aspects are part of the used BDEPQ. A previous study investigating the validity and reliability of the BDEPQ revealed a cut-off value of 23 points as the most appropriate threshold for indicating drug dependence [20]. During the treatment period of 12 weeks in this study, the results of the BDEPQ were either equal to or below this dependence-defining threshold value (23 points) and were significantly reduced at the end of observa- tion. In comparison, patients with a diagnosed (benzodiazepine) dependence have a reported BDEPQ value of $\geq 37.6$ [19]. Furthermore, there was no evidence that patients increased their daily dose during the observational period. A very good tolerability and compliance assessment completed the positive safety profile of the treatment.

\section{Limitations and Conclusion}

This non-interventional study provided the opportunity to document the effect of the passion flower extract on stress resistance (resilience) and QoL under everyday conditions and not in a strictly controlled setting of a clinical trial. The limitation of this type of study is the lack of a control group. Studies of mental and emotional disorders are especially prone to placebo effects and, so, in the absence of a placebo-controlled group, such effects cannot be ruled out in this study. Due to the high risk of developing drug dependency during prolonged treatment with benzodiazepines, such an active control group was not considered. A double-blind, randomized controlled trial is required to confirm the results.

In conclusion, the investigated dried ethanolic extract of passion flower may increase the resilience and QoL of patients with nervous restlessness while reducing symptoms and exhibiting good tolerability and compliance.

\section{Acknowledgments}

We thank all physicians and patients who participated in the study.

\section{Disclosure Statement}

Financial support was provided by PASCOE pharmazeutische Präparate $\mathrm{GmbH}$, Germany. Study management and execution as well as data evaluation were conducted by the Institute of Empirical Health Economics, Burscheid, Germany.

\section{References}

1 Franz M, Schepank H: [Mood disorders. Prevalence and course of unspecified functional disorders from the epidemiologic and psychosomatic viewpoint]. Z Arztl Fortbild Qualitatssich 1997;91:723-727.

2 Jahnsen K, Roser P, Hoffmann K: Probleme der Dauertherapie mit Benzodiazepinen und verwandten Substanzen. Dtsch Arztebl 2015;112:1-9.

3 Wohlmuth H, Penman KG, Pearson T, Lehmann RP Pharmacognosy and chemotypes of passion flower (Passiflora incarnata L.). Biol Pharm Bull 2010;33: 1015-1018.

4 Sarris J, McIntyre E, Camfield DA: Plant-based medicines for anxiety disorders, part 2: a review of clinical studies with supporting preclinical evidence. CNS Drugs 2013;27:301-319.

5 EMA (European Medicines Agency): Community herbal monograph on Passiflora incarnata L., herba. EMA/HMPC/669740/2013. EMA, 2014.
6 Appel K, Rose T, Fiebich B, Kammler T, Hoffmann C, Weiss G: Modulation of the gamma-aminobutyric acid (GABA) system by Passiflora incarnata L. Phytother Res 2010;25:838-843.

7 Hoffmann C, Trompetter I, Weiss G: Wirkmechanismus der Passionsblume aufgeklärt. Z Phytother 2014; 35:215-218.

8 Akhondzadeh S, Kashani L, Mobaseri M, Hosseini SH, Nikzad S, Khani M: Passion flower in the treatment of opiates withdrawal: a double-blind randomized controlled trial. J Clin Pharm Ther 2001;26:369-373.

9 Tabatabai SM, Dashti S, Doosti F, Hosseinzadeh H: Phytotherapy of opioid dependence and withdrawal syndrome: a review. Phytother Res 2014;28:811-830.

10 Ebrahimie M, Bahmani M, Shirzad H, Rafieian-Kopaei M, Saki K: A review study on the effect of Iranian herbal medicines on opioid withdrawal syndrome. J Evid Based Complementary Altern Med 2015;20:302-309.
11 Dimpfel W, Koch K, Weiss G: Single dose effects of Pascoflair ${ }^{\circledR}$ on current source density (CSD) of human EEG. Neurosci Med 2012;3:130-140.

12 Dimpfel W, Dipah GNC, Suliman S: Proof of effectiveness of Pascoflair ${ }^{\circledR}$ in subjects suffering from examination anxiety using quantitative EEG in combination with eye-tracking (EnkephaloVision). A double-blind, randomized, placebo controlled, 2-armed, phase IV study in parallel design. Pharmacol Pharm 2016;7:424442.

13 Empfehlungen des Bundesinstituts für Arzneimittel und Medizinprodukte und des Paul-Ehrlich-Instituts zur Planung, Durchführung und Auswertung von Anwendungsbeobachtungen vom 7. Juli 2010. $w w w$. bfarm.de/SharedDocs/Bekanntmachungen/DE/Arzneimittel/klinPr/bm-KlinPr-20100707-NichtinterventePrpdf.pdf?_blob $=$ publicationFile\& $v=6$ (last accessed January 31, 2017). 
14 Leppert K, Koch B, Brähler E, Strauss B: Die Resilienzskala (RS) - Überprüfung der Langform RS-25 und einer Kurzform RS-13. Klinische Diagnostik und Evaluation 2008;1:226-243.

15 Schumacher J, Leppert K, Gunzelmann T, Strauss B, Brähler E: Die Resilienzskala - Ein Fragebogen zur Erfassung der psychischen Widerstandsfähigkeit als Personmerkmal. Z Klin Psychol Psychiatrie Psychother 2005;53:16-39.

16 Brooks R: EuroQol: the current state of play. Health Policy 1996;37:53-72.

17 EuroQol Group: EuroQol - a new facility for the measurement of health-related quality of life. Health Policy 1990;16:199-208.

18 Claes C, Greiner W, Uber A, Graf von der Schulenburg JM: An interview-based comparison of the TTO and VAS values given to EuroQol states of health by the general German population; in Greiner W, Graf von der Schulenburg J-M, Piercy J (eds): Discussion Papers. EuroQol Plenary Meeting, 1-2 October 1998, Centre for Health Economics and Health Systems Research, University of Hannover, Germany. Hannover, UniVerlag Witte, 1999, pp 13-39.

19 Bailie A: Manual for the Benzodiazepine Dependence Questionaire - BDEPQ. Sydney, University of New South Wales, 1996

20 Minaya O, Fresan A, Cortes-Lopez JL, Nanni R, Ugalde $\mathrm{O}$ : The Benzodiazepine Dependence Questionnaire (BDEPQ): validity and reliability in Mexican psychiatric patients. Addict Behav 2011;36:874-877.
21 Hapke U, Maske UE, Scheidt-Nave C, Bode L, Schlack $\mathrm{R}$, Busch MA: [Chronic stress among adults in Germany: results of the German Health Interview and Examination Survey for Adults (DEGS1)]. Bundesgesundheitsblatt Gesundheitsforschung Gesundheitsschutz 2013;56:749-754.

22 Akhondzadeh S, Naghavi HR, Vazirian M, Shayeganpour A, Rashidi H, Khani M: Passion flower in the treatment of generalized anxiety: a pilot double-blind randomized controlled trial with oxazepam. J Clin Pharm Ther 2001;26:363-367.

23 Hellhammer J, Schubert M, Weiß G, Lebert J, Trompetter I: Stress \& Nervosität ausgeruht begegnen - Pascoflair $^{\circledR} 425 \mathrm{mg}$ in einer aktuellen placebo-kontrollierten Doppelblindstudie. Leipzig, Phytokongress, 2013, poster no. P06.

24 Kaviani N, Tavakoli M, Tabanmehr M, Havaei R: The efficacy of Passiflora incarnata Linnaeus in reducing dental anxiety in patients undergoing periodontal treatment. J Dent (Shiraz) 2013;14:68-72.

25 Movafegh A, Alizadeh R, Hajimohamadi F, Esfehani F, Nejatfar M: Preoperative oral Passiflora incarnata reduces anxiety in ambulatory surgery patients: a doubleblind, placebo-controlled study. Anesth Analg 2008; 106:1728-1732.

26 Hinz A, Klaiberg A, Brahler E, Konig HH: [The Quality of Life Questionnaire EQ-5D: modelling and norm values for the general population]. Psychother Psychosom Med Psychol 2006;56:42-48.

27 Grundmann O, Wang J, McGregor GP, Butterweck V: Anxiolytic activity of a phytochemically characterized Passiflora incarnata extract is mediated via the GABAergic system. Planta Med 2008;74:1769-1773.
28 Hapuarachchi JR, Chalmers AH, Winefield AH, BlakeMortimer JS: Changes in clinically relevant metabolites with psychological stress parameters. Behav Med 2003; 29:52-59.

29 Masteikova R, Bernatoniene J, Bernatoniene R, Velziene S: Antiradical activities of the extract of Passiflora incarnata. Acta Pol Pharm 2008;65:577-583.

30 Dos Santos KC, Borges TV, Olescowicz G, Ludka FK, Santos CA, Molz S: Passiflora actinia hydroalcoholic extract and its major constituent, isovitexin, are neuroprotective against glutamate-induced cell damage in mice hippocampal slices. J Pharm Pharmacol 2016;68: 282-291.

31 An F, Wang S, Yuan D, Gong Y, Wang S: Attenuation of oxidative stress of erythrocytes by plant-derived flavonoids, orientin and luteolin. Evid Based Complement Alternat Med 2016;2016:3401269.

32 Yoo $\mathrm{H}$, Ku SK, Lee T, Bae JS: Orientin inhibits HMGB1-induced inflammatory responses in HUVECs and in murine polymicrobial sepsis. Inflammation 2014;37:1705-1717

33 Liu Y, Lan N, Ren J, Wu Y, Wang ST, Huang XF, Yu Y Orientin improves depression-like behavior and BDNF in chronic stressed mice. Mol Nutr Food Res 2015;59: 1130-1142.

34 Tyrovolas S, Koyanagi A, Lara E, Santini ZI, Haro JM Mild cognitive impairment is associated with falls among older adults: findings from the Irish Longitudinal Study on Ageing (TILDA). Exp Gerontol 2016;75: $42-47$. 